\title{
STesearch Square
}

\section{Knowledge, Attitude, and Practices Regarding}

Childhood Tuberculosis Detection and Management Among Health Care Providers in Cambodia: A Cross-Sectional Study

\section{Yom An ( $\square$ anyomniph@gmail.com )}

School of Public Health, National Institute of Public Health, Cambodia

Alvin Kuo Jing Teo

National University of Singapore

Chan Yuda Huot

The National Centre for Tuberculosis and Leprosy Control (CENAT)

Sivanna Tieng

The National Centre for Tuberculosis and Leprosy Control (CENAT)

Kim Eam Khun

The National Centre for Tuberculosis and Leprosy Control (CENAT)

\section{Sok Heng Pheng}

The National Centre for Tuberculosis and Leprosy Control (CENAT)

\section{Chheng Lay Leng}

The National Centre for Tuberculosis and Leprosy Control (CENAT)

\section{Serongkea Deng}

World Health Organization

\section{Ngak Song}

The United States Agency for International Development

\section{Sotheara Nop}

The United States Agency for International Development

\section{Daisuke Nonaka}

University of the Ryukyus

\section{Siyan Yi}

KHANA Center for Population Health Research, Phnom Penh, Cambodia

\section{Research Article}

Keywords: Childhood TB, Case detection, Knowledge, attitude and practices, Infectious diseases, Lowand middle-income countries, Southeast Asia 
Posted Date: November 30th, 2021

DOI: https://doi.org/10.21203/rs.3.rs-1052066/v1

License: (c) (i) This work is licensed under a Creative Commons Attribution 4.0 International License. Read Full License

Version of Record: A version of this preprint was published at BMC Infectious Diseases on March 31st, 2022. See the published version at https://doi.org/10.1186/s12879-022-07245-1. 


\section{Abstract \\ Background}

The World Health Organization (WHO) estimated that $29 \%$ of global tuberculosis (TB) and almost $47 \%$ of childhood TB cases were not reported to national TB programs in 2019. In Cambodia, most childhood TB cases were reported from health facilities supported by the Global Fund to Fight AIDS, Tuberculosis, and Malaria in 2019. This study aimed to compare the healthcare providers' KAP on childhood TB case detection in ODs with high and low childhood TB case detection in Cambodia.

\section{Methods}

We conducted a cross-sectional study between November and December 2020 among healthcare providers in 10 purposively selected operational districts (ODs) with high childhood TB case detection and 10 ODs with low childhood TB case detection. A total of 110 healthcare providers from referral hospitals and 220 from health centers were interviewed. We collected information on socio-demographic characteristics, training, and KAP on childhood TB. Pearson's Chi-square or Fisher's exact and Student's $t$ tests were performed to explore the differences in KAP of healthcare providers from ODs with low vs. high childhood TB detection.

\section{Results}

Of the 330 respondents, 193 were from ODs with high childhood TB case detection, and $66.67 \%$ were from health centers. A significantly higher proportion (46.11\%) of respondents from ODs with high childhood TB case detection received training on childhood TB within the past two years than those from low childhood TB case detection ODs (34.31\%) ( $p=0.03)$. Key knowledge on childhood TB was not significantly different among respondents from ODs with high and low childhood TB case detection. A significantly higher proportion of respondents from ODs with high childhood TB case detection had a good attitude $(98.96 \%$ v.s. $97.08 \%, p=0.002)$ and performed good practices $(58.55 \%$ v.s. $45.26 \%, p=0.02)$ on contact investigation in the community than those from low childhood TB case detection ODs.

\section{Conclusions}

Healthcare providers from ODs with high childhood TB detection had better attitudes and practices towards childhood TB. The attitudes and practices need to be improved among healthcare providers in ODs with low case detection. Further investment in training and experience sharing on childhood TB case detection among healthcare providers is needed to improve childhood TB case detection.

\section{Background}


Tuberculosis (TB) remains a major global health problem. The estimated number of new TB cases in 2019 was 10 million (range 8.9 - 11.1 million) (1). The estimated proportion of childhood TB (age $<15$ years) incidence was about $12 \%$ of the total global TB incidence (1). Southeast Asia accounted for $44 \%$ of the total cases in the same year (2). In high-income countries, childhood TB constitutes $2-7 \%$ of all TB cases and is mainly found among immigrant populations (3). In contrast, childhood TB represents approximately $15-20 \%$ of all TB cases in low-income countries (3). A gap in TB case detection is also a big challenge. Based on the World Health Organization (WHO), approximately $29 \%$ of the global TB cases of all ages and $47 \%$ of TB cases in children under 15 years old were missed due to under-diagnosis and under-reporting (1).

Cambodia is one of the countries on track to reach the 2020 milestone to reduce $20 \%$ of TB incidence (2) and has been recently excluded from the global list of TB high-burden countries by WHO from 2021 to 2025 (4). Despite the transition, WHO still warrants continued attention, and TB will remain a priority in support. The Global TB Report 2019 estimated that TB incidence in Cambodia in 2018 was 49,000 (2), while only 30,017 cases ( $61 \%$ of the estimated incidence cases) were reported to the national TB program (NTP). Childhood TB was also under-reported in Cambodia. In 2019, 6,247 childhood TB cases were reported to NTP (5), which equated to $73.5 \%$ of the total of 8,500 childhood TB cases estimated by The Global TB Report 2019 (2).

Challenges in detecting childhood TB cases remain noticeable in many countries. Based on WHO, most countries have included contact investigation as a strategy to detect childhood TB cases in their national guidelines. Nevertheless, some of those activities have not been routinely implemented or scaled-up (6). Some studies have reported that the limited knowledge of healthcare providers remains a barrier for diagnosis, treatment, and prevention of childhood TB (6-8). A study conducted in Cambodia in 2017 found that only $72.5 \%$ of clinicians who worked at TB wards could identify five out of seven main childhood TB screening criteria, and they may not apply their knowledge into the practices (7).

In Cambodia, the Global Fund to Fight AIDS, Tuberculosis, and Malaria (Global Fund) is the main funding source to NTP, allocating the funds to NGOs for TB program implementation. In 2019, the Global Fund supported TB programs in 46 operational districts (ODs) (out of a total of 103 ODs), covering $56 \%$ of the total population in Cambodia (9). TB cases notified from the 46 ODs under the Global Fund support were 16,599 , equalling $55 \%$ of the total 30,017 TB cases notified in 2019 (5). Of a total of 6,247 childhood TB cases reported in 2019 (5), 4,014 cases (64\%) were reported from the 46 ODs under the coverage of the Global Fund. The remaining 34\% of childhood TB cases were reported from ODs without the Global Fund's support. Key Global Fund activities contributing to childhood TB case detection included TB screening at high burden communities and pagodas/mosques for key affected populations, fast-track mechanisms to send TB specimens or people with presumptive TB from villages to facilities with GeneXpert MTB/RIF ${ }^{\circledR}$ or X-ray, contact investigation at villages, supervision with onsite training, hospital linkage implementation, orientation and training to private pharmacy staff on presumptive TB cases identification and referrals, and orientation and training on TB case detection and diagnosis. 
Healthcare providers' knowledge, attitudes, and practices (KAP) are key factors contributing to TB case detection and better management (6-8). However, no previous studies have evaluated healthcare providers' KAP from the settings with high and low childhood TB case detection in Cambodia. Therefore, this study aimed to compare the healthcare providers' KAP on childhood TB case detection in ODs with the high and low childhood TB case detection in Cambodia. The study's findings will help to inform current TB programs in both sites to improve the interventions, particularly childhood TB case detection.

\section{Methods}

\section{Study setting}

We conducted a quantitative cross-sectional study between November and December 2020. Healthcare providers were recruited from 10 ODs with low and 10 ODs with high childhood TB case detection in 13 provinces. In each $O D$, there is one referral hospital (RH) covering about 100,000 population and several health centers (HCs), each serving about 10,000 population (10). We purposively selected the 20 ODs to ensure equal representation of urban and rural localities. In the selected study sites, there were a total of $20 \mathrm{RHs}$ and $208 \mathrm{HCs}$.

\section{Sample size}

At the RHs, the number of healthcare providers varies depending on the level of RHs. Complementary package activities 1 (CPA1) refers to RHs with "no grand surgery (without general anesthesia); CPA2 refers to RHs with grand surgery and emergency care services; and CPA3 refers to RHs with grand surgery and various specialized services such ears, nose, and throat (ENT) and ophthalmology (11). Six physicians working directly or indirectly on TB in each $\mathrm{RH}$ were selected for the interviews. With an assumption of $10 \%$ of the non-response rate, the minimum required sample size was 132 . However, if more than six physicians were working directly or indirectly with childhood TB, all of them would be selected for interviews.

In the Minimum Package of Activities (MPA) for HC Development 2007, the minimum number of staff required to ensure the proper function of an $\mathrm{HC}$ is at least eight people (12). Healthcare services provided at $\mathrm{HC}$ include outpatient consultation services; maternal, newborn, child, and reproductive health services; infectious diseases services; non-communicable diseases services; and health education and health promotion services (12). In Cambodia, at least two outpatient consultation and communicable disease service staff were directly or indirectly linked to childhood TB services. Therefore, among the $208 \mathrm{HCs}$ in the selected ODs, at least $416 \mathrm{HC}$ staff were eligible. With a 5\% margin error, $95 \%$ confidence interval (CI), and $50 \%$ of $\mathrm{HC}$ staff correctly identified and referred presumptive childhood TB cases to RHs for TB diagnosis, and a $10 \%$ non-response rate, the minimum required sample size was 220 . With two staff to be selected from one $\mathrm{HC}, 110 \mathrm{HCs}$ were randomly selected. The selection of HCs was based on the proportion of the number of HCs in each OD.

\section{Data collection procedures}


The questionnaire was initially developed in English and then translated into the Khmer language. It was then pretested and revised accordingly before being administered by trained data collectors. The interviews were face-to-face using a paper-based questionnaire, and each interview took about 30 to 40 min to complete. Respondents received a compensation gift valued at about one US dollar. The data collection team leader checked the collected data for completeness and accuracy.

\section{Variables and measurements}

A structured questionnaire was developed based on tools adapted from a previous study (7), a childhood TB treatment guideline training manual developed by NTP (13), and the current TB-Speed research project implemented by Institut Pasteur du Cambodge through an oral communication with the NTP in February 2020. The tools were tailored to the study settings and objectives through discussions with a research team at the National Center for Tuberculosis and Leprosy Control (CENAT). Socio-demographic characteristics included age, sex, education, role at the health facility (head of HC or TB staff), departments (infectious diseases, outpatient department or consultation services, medical ward, surgical ward, pediatric ward, or emergency ward), and training on childhood TB. Knowledge on childhood TB included the causes of TB, transmission routes, signs and symptoms, characteristics of lymph nodes that implied TB, and diagnostic criteria for childhood TB. For attitude, we collected participants' perceptions on contact investigation, training on childhood TB, TB diagnostic tools, laboratory services, and human resources for childhood TB. Information on practices included contact investigation performance, presumptive TB referrals for diagnostic work-ups, and TB treatment. Attitude and practices were measured using four levels of the Likert scale (14). We used four levels of respondents' agreement -"strongly agree," "agree," "disagree," and "strongly disagree")-for each of the seven statements toward childhood TB case detection to measure respondents' attitude. Similarly, four statements about practices toward childhood TB case detection were captured using "always," "often," "sometime," or "never."

After data cleaning, recoding was done for some variables. We grouped categories for age, knowledge on TB signs and symptoms, knowledge on groups of children at high risk of developing TB, characteristics of lymph nodes implied TB, and screening criteria for childhood TB to facilitate the subsequent analyses. For attitudes, respondents who answered "always" and "often" to the statements were considered to have a positive attitude towards childhood TB case detection. Similarly, good practices were classified when respondents answered "always" and "often" to the positive statements toward childhood TB case detection.

\section{Data management and analyses}

Collected data were double entered into EpiData 3.1 (The EpiData Association, Odense, Denmark) and then exported into STATA 14.2 (Stata Corp, College Station, Texas). Respondents were categorized into two groups based on whether they were from ODs with high and low childhood TB case detection. Knowledge on childhood TB was categorized as follows: knowing symptoms and signs of childhood TB ( $<4$ vs. $\geq 4$ ), knowing characteristics of enlarged lymph nodes implied TB ( $<3$ vs. $\geq 3$ ), and knowing screening criteria for childhood TB ( $<4$ vs. $\geq 4)$. 
Descriptive analyses were conducted to calculate frequency and proportion for categorical variables and mean and standard deviation (SD) for continuous variables. In bivariate analyses, we used Pearson's Chisquare (or Fisher's exact test when a cell count was smaller than five) for categorical variables and Student's $t$-test for continuous variables to explore the differences in characteristics and KAP of healthcare providers from ODs with low vs. high childhood TB detection. A $p<0.05$ was considered statistically significant.

\section{Ethical consideration}

This study was conducted after obtaining ethical clearances from the National Ethics Committee for Health Research (NECHR) in Cambodia (ref. 234/NECHR) and the Ethics Review Committee of the World Health Organization Western Pacific Regional Office (WPRO-ERC) (ID: 2020.8.CAM.3.STB). All methods were carried out in accordance with national guidelines and regulations. The objectives, procedures, risks, and benefits in participating in this study were explained to each participant. All participants provided a written informed consent for the study. Data from all participants were treated anonymously, without a name, address, and personal information in the records. Information provided was handled strictly confidential.

\section{Results}

\section{Socio-demographic characteristics}

Socio-demographic characteristics of the study participants are shown in Table 1. In total, we included 193 and 137 respondents from ODs with high and low childhood TB case detection, respectively. About half of the participants were younger than 45 years old, and the majority were male. A significantly higher proportion of respondents from ODs with high childhood TB case detection received training on childhood TB within the past two years than those with low childhood TB case detection $(46.11 \%$ vs. $34.31 \%, p=0.03)$. Other characteristics did not differ significantly between participants from both sites. 
Table 1

Demographic characteristics of healthcare providers from ODs with high and low childhood TB case detection

\begin{tabular}{|c|c|c|c|c|}
\hline Characteristics & $\begin{array}{l}\text { Total } \\
(n= \\
330)\end{array}$ & $\begin{array}{l}\text { ODs with high } \\
\text { childhood TB case } \\
\text { detection } \\
(n=193)\end{array}$ & $\begin{array}{l}\text { ODs with low } \\
\text { childhood TB case } \\
\text { detection } \\
(n=137)\end{array}$ & \\
\hline & $\mathrm{n}(\%)$ & $\mathrm{n}(\%)$ & $\mathrm{n}(\%)$ & $\begin{array}{l}\mathrm{P}- \\
\text { value }\end{array}$ \\
\hline Workplace & & & & 0.43 \\
\hline District referral hospital & $\begin{array}{l}110 \\
(33.33)\end{array}$ & $61(31.61)$ & $49(35.77)$ & \\
\hline Health center & $\begin{array}{l}220 \\
(66.67)\end{array}$ & $132(68.39)$ & $88(64.23)$ & \\
\hline Age in years & & & & 0.58 \\
\hline$<35$ & $\begin{array}{l}107 \\
(32.42)\end{array}$ & $64(33.16)$ & $43(31.39)$ & \\
\hline $35-44$ & $\begin{array}{l}75 \\
(22.73)\end{array}$ & $47(24.35)$ & $28(20.44)$ & \\
\hline $45-54$ & $\begin{array}{l}121 \\
(36.67)\end{array}$ & $65(33.68)$ & $56(40.88)$ & \\
\hline$\geq 55$ & $\begin{array}{l}27 \\
(8.18)\end{array}$ & $17(8.81)$ & $10(7.30)$ & \\
\hline Sex, Male & $\begin{array}{l}253 \\
(76.67)\end{array}$ & $142(73.58)$ & $111(81.02)$ & 0.12 \\
\hline \multicolumn{5}{|l|}{$\begin{array}{l}\text { Working service(s) of } \\
\text { respondents from referral } \\
\text { hospitals }^{*}\end{array}$} \\
\hline $\begin{array}{l}\text { Infectious diseases service: TB, } \\
\text { HIV, malaria }\end{array}$ & $\begin{array}{l}23 \\
(20.91)\end{array}$ & $13(21.31)$ & $10(20.41)$ & 0.91 \\
\hline Consultation service (OPD) & $\begin{array}{l}31 \\
(28.18)\end{array}$ & $20(32.79)$ & $11(22.45)$ & 0.23 \\
\hline Medical service & $\begin{array}{l}34 \\
(30.91)\end{array}$ & $17(27.87)$ & 17 (34.69) & 0.44 \\
\hline Surgical service & $\begin{array}{l}13 \\
(11.82)\end{array}$ & $8(13.11)$ & $5(10.20)$ & 0.64 \\
\hline \multicolumn{5}{|c|}{$\begin{array}{l}\text { Abbreviations: OD, operational district; TB, tuberculosis, HIV, human immunodeficiency virus, OPD, } \\
\text { outpatient department. }\end{array}$} \\
\hline
\end{tabular}




\begin{tabular}{|c|c|c|c|c|}
\hline Characteristics & $\begin{array}{l}\text { Total } \\
(n= \\
330)\end{array}$ & $\begin{array}{l}\text { ODs with high } \\
\text { childhood TB case } \\
\text { detection } \\
(n=193)\end{array}$ & $\begin{array}{l}\text { ODs with low } \\
\text { childhood TB case } \\
\text { detection } \\
(n=137)\end{array}$ & \\
\hline Pediatric service & $\begin{array}{l}26 \\
(23.64)\end{array}$ & $14(22.95)$ & $12(24.49)$ & 0.85 \\
\hline Emergency service & $\begin{array}{l}24 \\
(21.82)\end{array}$ & $14(22.95)$ & $10(20.41)$ & 0.75 \\
\hline $\begin{array}{l}\text { Role of respondents from } \\
\text { health centers }\end{array}$ & & & & 0.87 \\
\hline Head of the health center & $\begin{array}{l}83 \\
(37.73)\end{array}$ & $47(56.63)$ & $36(43.37)$ & \\
\hline OPD staff & $\begin{array}{l}30 \\
(13.64)\end{array}$ & $19(63.33)$ & $11(36.67)$ & \\
\hline Staff in charge of TB & $\begin{array}{l}82 \\
(37.27)\end{array}$ & $50(60.98)$ & $32(39.02)$ & \\
\hline Others & $\begin{array}{l}25 \\
(11.36)\end{array}$ & $16(64.00)$ & $9(39.00)$ & \\
\hline Highest degree of education & & & & 0.19 \\
\hline Specialized doctor & $\begin{array}{l}8 \\
(2.42)\end{array}$ & $4(2.07)$ & $4(2.92)$ & \\
\hline General doctor & $\begin{array}{l}101 \\
(30.61)\end{array}$ & $51(26.42)$ & $50(36.50)$ & \\
\hline Medical assistant & $\begin{array}{l}37 \\
(11.21)\end{array}$ & $27(13.99)$ & $10(7.30)$ & \\
\hline Nurse & $\begin{array}{l}142 \\
(43.03)\end{array}$ & $84(43.52)$ & $58(42.34)$ & \\
\hline Midwife & $\begin{array}{l}30 \\
(9.09)\end{array}$ & $18(9.33)$ & $12(2.19)$ & \\
\hline Other & $\begin{array}{l}12 \\
(3.64)\end{array}$ & $9(4.66)$ & $3(2.19)$ & \\
\hline $\begin{array}{l}\text { Experience in working with TB } \\
\text { or presumptive TB }\end{array}$ & & & & 0.96 \\
\hline$<1$ year & $\begin{array}{l}113 \\
(43.24)\end{array}$ & $65(33.68)$ & $48(35.04)$ & \\
\hline
\end{tabular}

Abbreviations: OD, operational district; TB, tuberculosis, HIV, human immunodeficiency virus, OPD, outpatient department.

*Some of them worked in more than one service. 


\begin{tabular}{|llll|}
\hline Characteristics & $\begin{array}{l}\text { Total } \\
(\boldsymbol{n}= \\
\mathbf{3 3 0})\end{array}$ & $\begin{array}{l}\text { ODs with high } \\
\text { childhood TB case } \\
\text { detection } \\
(\boldsymbol{n}=\mathbf{1 9 3})\end{array}$ & $\begin{array}{l}\text { ODs with low } \\
\text { childhood TB case } \\
\text { detection } \\
(\boldsymbol{n}=137)\end{array}$ \\
\hline 1 - 5 years & $\begin{array}{l}113 \\
(43.24)\end{array}$ & $65(33.68)$ & $48(35.04)$ \\
\hline 6 - 10 years & $\begin{array}{l}52 \\
(15.76)\end{array}$ & $31(16.06)$ & $21(15.33)$ \\
\hline$>10$ years & $\begin{array}{l}52 \\
(15.76)\end{array}$ & $32(16.58)$ & $20(14.60)$ \\
\hline $\begin{array}{l}\text { Received training on childhood } \\
\text { TB within the past two years }\end{array}$ & $\begin{array}{l}136 \\
(41.21)\end{array}$ & $89(46.11)$ & $47(34.31)$ \\
\hline $\begin{array}{l}\text { Abbreviations: OD, operational district; TB, tuberculosis, HIV, human immunodeficiency virus, OPD, } \\
\text { outpatient department. }\end{array}$ & \\
\hline
\end{tabular}

\section{Childhood Tb Knowledge}

Table 2 summarizes the knowledge of healthcare providers on childhood TB. In general, knowledge of respondents from ODs with high and low childhood TB case detection on causes of TB, routes of TB transmission, groups of children at high risk of developing TB, TB signs and symptoms, characteristics of lymph nodes implying TB, and screening criteria for childhood TB were not significantly different. However, a significantly higher proportion of providers from ODs with low case detection correctly mentioned that weight loss or not gaining weight is a symptom of childhood TB than those with high case detection. Knowledge on the level of fever implying TB $\left(>38.0^{\circ} \mathrm{C}\right)$ was significantly higher among participants from ODs with high case detection than that among participants from ODs with low case detection. 
Table 2

Knowledge of healthcare providers on childhood TB

\begin{tabular}{|c|c|c|c|}
\hline \multirow[t]{2}{*}{ Variables } & $\begin{array}{l}\text { ODs with high } \\
\text { childhood TB case } \\
\text { detection } \\
(n=193)\end{array}$ & $\begin{array}{l}\text { ODs with low } \\
\text { childhood TB case } \\
\text { detection } \\
(n=137)\end{array}$ & \\
\hline & $\mathrm{n}(\%)$ & $\mathrm{n}(\%)$ & $\begin{array}{l}\mathrm{P}- \\
\text { value }\end{array}$ \\
\hline TB is caused by bacteria & $171(88.60)$ & $121(88.32)$ & 0.94 \\
\hline TB is a transmissible disease & $191(98.96)$ & $137(100.00)$ & 0.23 \\
\hline $\begin{array}{l}\text { TB is spread through expectorated droplet } \\
\text { spread }\end{array}$ & $191(98.96)$ & $137(100.00)$ & 0.23 \\
\hline $\begin{array}{l}\text { Transmission is reduced after a smear- } \\
\text { positive PTB received treatment for two } \\
\text { weeks }\end{array}$ & $161(83.42)$ & $116(84.67)$ & 0.76 \\
\hline $\begin{array}{l}\text { Knowing at least two out of three groups of } \\
\text { children at high risk of developing TB below }\end{array}$ & $119(61.66)$ & $98(71.53)$ & 0.06 \\
\hline Age less than 1-year-old & $48(24.87)$ & $32(23.36)$ & 0.75 \\
\hline Living with smear-positive PTB & $178(92.23)$ & $129(94.16)$ & 0.50 \\
\hline Living with HIV/AIDS & $111(57.51)$ & $92(67.15)$ & 0.08 \\
\hline $\begin{array}{l}\text { Knew at least four out of eight childhood } \\
\text { TB symptoms/signs below }\end{array}$ & $159(82.38)$ & $118(86.13)$ & 0.36 \\
\hline Chronic cough & $184(95.34)$ & $126(91.97)$ & 0.21 \\
\hline Persistent fever & $171(88.60)$ & $118(86.13)$ & 0.50 \\
\hline Weight loss or not gain weight & $175(90.67)$ & $132(96.35)$ & 0.046 \\
\hline Night sweats & $144(74.61)$ & $108(78.83)$ & 0.37 \\
\hline Bone deformity & $33(17.10)$ & $18(13.14)$ & 0.33 \\
\hline Enlarge lymph nodes & $116(60.10)$ & $95(69.34)$ & 0.09 \\
\hline Arthralgia & $22(11.40)$ & $17(12.41)$ & 0.78 \\
\hline Asthenia & $83(43.01)$ & $59(56.93)$ & 0.99 \\
\hline $\begin{array}{l}\text { Knew duration of cough that implies TB ( } \geq \\
2 \text { weeks) }\end{array}$ & $156(80.83)$ & $114(83.21)$ & 0.58 \\
\hline
\end{tabular}

Abbreviations: TB, tuberculosis; PTB, pulmonary TB; TST, tuberculin skin test; RH, district referral hospital; $\mathrm{HC}$, health center; SD, standard deviation. 


\begin{tabular}{|c|c|c|c|}
\hline \multirow[t]{2}{*}{ Variables } & $\begin{array}{l}\text { ODs with high } \\
\text { childhood TB case } \\
\text { detection } \\
(n=193)\end{array}$ & $\begin{array}{l}\text { ODs with low } \\
\text { childhood TB case } \\
\text { detection } \\
(n=137)\end{array}$ & \\
\hline & $\mathrm{n}(\%)$ & $\mathrm{n}(\%)$ & $\begin{array}{l}\text { P- } \\
\text { value }\end{array}$ \\
\hline $\begin{array}{l}\text { Knew level of fever that implies TB (> } \\
\left.38.0^{\circ} \mathrm{C}\right)\end{array}$ & $84(43.52)$ & $40(29.20)$ & 0.008 \\
\hline $\begin{array}{l}\text { Knew at least three out of six } \\
\text { characteristics of enlarged lymph nodes } \\
\text { implied TB below }\end{array}$ & $87(45.31)$ & $62(45.59)$ & 0.96 \\
\hline Enlarge $\geq 2 \mathrm{~cm}$ & $139(72.40)$ & $87(63.97)$ & 0.10 \\
\hline Painless & $86(44.79)$ & $71(52.21)$ & 0.19 \\
\hline Asymmetric & $105(54.69)$ & $67(49.26)$ & 0.33 \\
\hline Firm, matted or discreet & $64(33.33)$ & $40(29.41)$ & 0.45 \\
\hline Persistent (> 2 weeks) & 60 (31.09) & $47(34.31)$ & 0.54 \\
\hline $\begin{array}{l}\text { Unresponsive to other treatment (such as } \\
\text { antibiotics) }\end{array}$ & $49(25.52)$ & $33(24.26)$ & 0.80 \\
\hline $\begin{array}{l}\text { Knew at least four out of seven screening } \\
\text { criteria for childhood TB below }\end{array}$ & $145(75.13)$ & $109(79.56)$ & 0.35 \\
\hline Enlarge lymph nodes & $146(76.04)$ & $110(80.29)$ & 0.36 \\
\hline Persistent cough & $166(86.46)$ & $119(86.86)$ & 0.92 \\
\hline Persistent wheezing & $22(11.46)$ & $19(13.87)$ & 0.51 \\
\hline Weight loss or not gain weight & $170(88.54)$ & $124(90.51)$ & 0.57 \\
\hline Fever & $164(85.42)$ & $111(80.02)$ & 0.29 \\
\hline Night sweat & $87(45.08)$ & $62(45.26)$ & 0.97 \\
\hline Close contact to smear-positive PTB & $117(60.94)$ & $79(57.66)$ & 0.55 \\
\hline Total knowledge score (total 30), mean (SD) & $18.68(4.74)$ & $18.74(4.36)$ & 0.90 \\
\hline
\end{tabular}

\section{Attitude Toward Childhood Tb}


The attitudes of healthcare providers toward childhood TB are presented in Figure 1. The proportions of participants who "strongly agreed" or "agreed" that they had received adequate diagnostic tools, training, and staff to treat childhood TB were significantly higher among participants from ODs with high childhood TB case detection than those from ODs with lower childhood TB case detection. Participants from ODs with high childhood TB case detection were also significantly more likely to respond that they would ask people with smear-positive pulmonary TB to bring their close contacts for TB diagnostic workup. Interestingly, most respondents from HCs in ODs with high and low childhood TB case detection "strongly agreed" or "agreed" to refer children who might have TB for TB diagnosis work-up. Overall, a significantly lower proportion of participants from ODs with low case detection perceived that there was sufficient TB diagnostic tools, training on childhood TB, and staff to treat childhood TB. They were significantly less likely to ask people with smear-positive PTB to bring close contacts for TB screening.

\section{Practices Of Childhood Tb}

As shown in Table 3, good practices on contact investigation within the community were significantly higher among participants from ODs with high childhood TB case detection than those with low childhood TB case detection ( $p=0.02)$. A remarkable higher proportion $(76.17 \%)$ of participants from ODs with high childhood TB case detection "strongly agreed" or "agreed" to ask index TB patients to bring their close contacts to health facilities for TB screening than those from ODs with low childhood TB case detection $(66.42 \%)$, although it was not statistically significant $(p=0.052)$. It is noted that a high proportion of respondents from both comparison groups reported good practices on referring children who might have TB for TB diagnostic work-up, $84.46 \%$ and $79.56 \%$ among participants from ODs with high and low childhood TB case detection, respectively.

Table 3 Practices of childhood TB among healthcare providers from ODs with high and low childhood TB case detection 


\begin{tabular}{|c|c|c|c|c|c|}
\hline \multirow[t]{3}{*}{ Practice activities } & \multirow{2}{*}{\multicolumn{2}{|c|}{$\begin{array}{l}\text { ODs with high } \\
\text { childhood TB case } \\
\text { detection } \\
(n=193)\end{array}$}} & \multirow{2}{*}{\multicolumn{3}{|c|}{$\begin{array}{l}\text { ODs with low childhood } \\
\text { TB case detection }(n= \\
\text { 137) }\end{array}$}} \\
\hline & & & & & \\
\hline & $n(\%)$ & $n(\%)$ & $n(\%)$ & $n(\%)$ & $\begin{array}{l}P \\
\text { value }\end{array}$ \\
\hline \multicolumn{6}{|c|}{$\begin{array}{l}\text { Ask index TB patients to bring their } \\
\text { close contacts to health facilities for TB } \\
\text { screening }\end{array}$} \\
\hline Poor practice & 46 & 23.83 & 46 & 33.58 & \multirow[t]{2}{*}{0.05} \\
\hline Good practice & 147 & 76.17 & 91 & 66.42 & \\
\hline \multicolumn{6}{|c|}{$\begin{array}{l}\text { Perform contact investigation in the } \\
\text { community }\end{array}$} \\
\hline Poor practice & 80 & 41.45 & 75 & 54.74 & \multirow[t]{2}{*}{0.02} \\
\hline Good practice & 113 & 58.55 & 62 & 45.26 & \\
\hline \multicolumn{6}{|c|}{$\begin{array}{l}\text { Refer children who might have for TB } \\
\text { diagnosis work-up }\end{array}$} \\
\hline Poor practice & 30 & 15.54 & 28 & 20.44 & \multirow[t]{2}{*}{0.25} \\
\hline Good practice & 163 & 84.46 & 109 & 79.56 & \\
\hline \multicolumn{6}{|l|}{ Treat childhood TB } \\
\hline Poor practice & 100 & 51.81 & 68 & 49.64 & \multirow[t]{2}{*}{0.70} \\
\hline Good practice & 93 & 48.19 & 93 & 48.19 & \\
\hline \multicolumn{6}{|c|}{$\begin{array}{l}\text { Start TB treatment before diagnosis } \\
\text { confirmation }\end{array}$} \\
\hline Poor practice ${ }^{\star}$ & 12 & 6.22 & 6 & 4.38 & \multirow[t]{2}{*}{0.47} \\
\hline Good practice $^{*}$ & 181 & 93.78 & 131 & 95.62 & \\
\hline
\end{tabular}

Abbreviations: TB: tuberculosis; OD: operational district.

Good practice: Respondents answering "always and often" to the questionnaire.

Poor practice: Respondents answering "sometime and never" to the questionnaire.

"Good practice: Respondents answering "sometime and never" to the questionnaire.

*Poor practice: Respondents answering "always and often" to the questionnaire. 


\section{Discussion}

This study assessed the KAP of healthcare providers from ODs with high and low childhood TB case detection in Cambodia. The results showed that knowledge on causes of TB, TB transmission routes, symptoms and signs of childhood TB, characteristics of lymph nodes implying TB, and screening criteria for childhood TB were not significantly different among healthcare providers from the OD groups. Most respondents knew that TB is caused by bacteria, similar to findings in a study in Iraq $(15,16)$ but higher than those in Saudi Arabia (17). In our study, knowledge on TB transmission routes was relatively high among healthcare providers from ODs with high childhood TB case detection. This finding is similar to the finding of the study in Iraq (15) and Nigeria (18) but higher than other studies $(17,19-21)$. Over $80 \%$ of healthcare providers from ODs with high childhood TB case detection knew four or more childhood TB signs and symptoms. Providers' knowledge of specific TB signs and symptoms is also noticeably high, especially on the four basic TB symptoms (cough, fever, weight loss or not gaining weight, and night sweat).

Knowledge of cough duration implying TB is high in our study, which is similar to a previous study in Cambodia (7), lower than a study in Nigeria (18), and higher than a study in Ethiopia (19). For fever, although a high proportion of respondents knew that fever is a symptom of TB, a low proportion of them correctly specified the level of fever $\left(>38.0^{\circ} \mathrm{C}\right)$, implying TB. The proportion is lower than a previous study in Cambodia (7). Less than haft of the total study population knew three or more characteristics of lymph nodes implying TB, which is far lower than findings in a previous study in Cambodia (7). This difference of knowledge might be due to different target populations selected for the studies. In our study, healthcare providers were selected from both referral hospitals and health centers, while participants in the previous study were selected only from referral hospitals. Nevertheless, the poor knowledge among health providers indicates the need for training healthcare providers on childhood TB since it has important clinical implications for lymph node TB diagnosis. Knowledge of screening criteria for those who might have TB was relatively high among respondents from both OD groups. However, a low proportion of respondents from both groups knew that a smear-positive PTB patient's close contact was a screening criterion. Since contact investigation plays a key role in TB case detection $(22,23)$, healthcare providers must widely understand this.

Healthcare providers' attitude toward childhood TB case detection is critical. Our results suggest that most respondents had a positive attitude toward childhood TB case detection. Almost all respondents from HCs strongly agreed or agreed to refer children who might have TB for TB diagnosis work-up. However, a significantly higher proportion of providers from ODs with high childhood TB case detection strongly agreed and agreed to bring family members and close contacts of smear-positive PTB for TB screening. This finding suggests that the attitude toward contact investigation of providers from ODs with low childhood TB case detection needs to be strengthened. A significantly higher proportion of respondents from ODs with high childhood TB case detection strongly agreed that staff in their health facilities received adequate childhood TB training than those from ODs with low childhood TB case detection. Therefore, refresher training on childhood TB should be provided to providers in ODs with high 
childhood TB case detection. Overall, healthcare providers in this study agreed that there was a lack of human resources for TB screening, indicating the need for more resource allocation in those health facilities.

Healthcare providers from ODs with high childhood TB case detection performed better practices on contact investigation within their health facilities and in the community than those from ODs with low case detection. These better practices could be due to more supports available in facilities under the Global Fund's coverage and may contribute to higher childhood TB case detection $(24,25)$. The NTP should consider strengthening good practices on contact investigation in health facilities and communities in ODs not supported by the Global Fund. Other good practices toward childhood TB case detection, such as referrals of children who might have TB for TB diagnostic work-up, were also higher in ODs with Global Fund's supports, although the differences were not statistically significant. Improving these good practices needs to be taken into account to improve childhood TB case detection.

This study has a few limitations. Our primary objective was to identify operational challenges in childhood TB case detection in ODs with reported high and low childhood TB cases. During the data collection, some respondents from low childhood TB detection ODs received intervention from other organizations. So KAP of respondents from ODs with low childhood TB case detection was contaminated by the intervention. Despite so, we found that there were some critical differences between the two groups. Should contamination not occur, we opined that the results would bias away from the null, differences between the two groups would be more apparent. Due to the shortage of staff working in the hospitals, the sample size for respondents from RHs was smaller than the target, limiting the generalizability of the findings. Also, we collected information through face-to-face questionnaire interviews prone to reporting bias. Similarly, we did not measure actual practices by observing staff behaviors in a specific situation or using a simulated client method. Hence, there may have been an overestimation of good practices among providers from both OD groups.

\section{Conclusions}

The level of knowledge on childhood TB among healthcare providers from ODs with high and low childhood TB case detection was similar. However, a significantly higher proportion of providers with high childhood TB case detection received training on childhood TB within the past two years. In addition, attitudes and practices toward childhood TB case detection were better among healthcare providers from ODs with high childhood TB case detection than those from ODs with low childhood TB case detection. Hence, investment should be considered to translate knowledge into action to ensure that children with presumptive TB will be duly screened, detected, and treated in low TB case detection ODs. Expanding the training, technical and financial supports to ODs with low childhood TB case detection should be considered to improve childhood TB case detection in Cambodia.

\section{Declarations}




\section{Competing interests}

The authors declare that they have no competing interests.

\section{Ethical approval and consent to participate}

This study was conducted after obtaining ethical clearances from the National Ethics Committee for Health Research (NECHR) in Cambodia (ref. 234/NECHR) and the Ethics Review Committee of the World Health Organization Western Pacific Regional Office (WPRO-ERC) (ID: 2020.8.CAM.3.STB). All methods were carried out in accordance with national guidelines and regulations. The objectives, procedures, risks, and benefits in participating in this study were explained to each participant. All participants provided a written informed consent for the study. Data from all participants were treated anonymously, without a name, address, and personal information in the records. Information provided was handled strictly confidential.

\section{Consent for publication}

All authors reviewed and approved the final manuscript.

\section{Availability of data and materials}

Data and materials are available based on requests.

\section{Funding}

The study was funded by the United States Agency for International Development (USAID) through the World Health Organization

\section{Authors' contributions}

Y.A., A.K.J.T., S.V.T., K.E.K., S.P., S.D., N.S., and S.Y. conceptualized and designed the study. Y.A., K.E.K., S.N., C.L.L., and C.Y.H. supported project implementation, data collection and data source. Y.A., S.Y., D.N., A.K.J.T., and K.E.K. supported the data management, statistical analysis of the study and drafting the manuscript. All authors reviewed and approved the final manuscript.

\section{Acknowledgements}

We would like to thank the United States Agency for International Development (USAID) for funding support through the World Health Organization and the Cambodia Committee for TB Research members for technical inputs. We also thank data collection teams, provincial health departments, operational districts, referral hospitals, and health centers for supporting the data collection and study participants for participating in the study.

\section{Authors' information (optional)}


${ }^{1}$ Sustaining Technical and Analytical Resources (STAR), USAID, ${ }^{2}$ University of the Ryukyus, ${ }^{3}$ School of Public Health, National Institute of Public Health, Cambodia, ${ }^{4}$ Saw Swee Hock School of Public Health, National University of Singapore, National University Health System, Singapore, ${ }^{5}$ The National Centre for Tuberculosis and Leprosy Control (CENAT), ${ }^{6}$ World Health Organization, ${ }^{7}$ The United States Agency for International Development, ${ }^{8}$ KHANA Center for Population Health Research, Phnom Penh, Cambodia, and ${ }^{9}$ Center for Global Health Research, Touro University California, Vallejo, California, USA.

*Corresponding author: anyomniph@gmailcom

\section{References}

1. World Health Organization. Global tuberculosis report 2020: executive summary. 2020.

2. World Health Organization. Global tuberculosis report 2019: executive summary. 20199240016090.

3. Kruk A, Gie RP, Schaaf HS, Marais BJ. Symptom-based screening of child tuberculosis contacts: improved feasibility in resource-limited settings. Pediatrics. 2008;121(6):e1646-e52.

4. World Health Organization. WHO global lists of high burden countries for TB, MDR/RR-TB and TB/HIV, 2021-2025. 2021.

5. National Center for Tuberculosis and Leprosy Control (CENAT). Tuberculosis Report 2019. 2019.

6. World Health Organization. Roadmap towards ending TB in children and adolescents. 2018.

7. Frieze JB, Yadav R-P, Sokhan K, Ngak S, Khim TB. Examining the quality of childhood tuberculosis diagnosis in Cambodia: a cross-sectional study. BMC public health. 2017;17(1):1-9.

8. Noé A, Ribeiro RM, Anselmo R, Maixenchs M, Sitole L, Munguambe K, et al. Knowledge, attitudes and practices regarding tuberculosis care among health workers in Southern Mozambique. BMC pulmonary medicine. 2017;17(1):1-7.

9. Ministry of Health. Cambodia Health Management Information System 2019. Available from: http://hismohcambodia.org/public/index.php.

10. Department of Planning and Health Information. Health Strategic Plan 2016-2020. 2016.

11. Ministry of Health. National Guidelines on Complementary Package of Activities for Referral Hospital Development from 2006 to 2010. 2006.

12. Ministry of Health. Guidelines on Minimum Package of Activities For Health Center Development 2008-2015.2007.

13. National Center for Tuberculosis and Leprosy Control. Childhood TB Training Manual for Referral Hospitals. 2019.

14. Nemoto T, Beglar D, editors. Likert-scale questionnaires. JALT 2013 conference proceedings; 2014.

15. Hashim DS, Al Kubaisy W, Al Dulayme A. Knowledge, attitudes and practices survey among health care workers and tuberculosis patients in Iraq. East Mediterr Health J. 2003;9(4):718-31. 
16. Hoa NP, Diwan VK, Thorson AE. Diagnosis and treatment of pulmonary tuberculosis at basic health care facilities in rural Vietnam: a survey of knowledge and reported practices among health staff. Health Policy. 2005;72(1):1-8.

17. Alotaibi B, Yassin Y, Mushi A, Maashi F, Thomas A, Mohamed G, et al. Tuberculosis knowledge, attitude and practice among healthcare workers during the 2016 Hajj. PloS one. 2019;14(1):e0210913.

18. Akande PA. Knowledge and practices regarding tuberculosis infection control among nurses in Ibadan, south-west Nigeria: a cross-sectional study. BMC Health Services Research. 2020;20(1):280.

19. Sima BT, Belachew T, Abebe F. Health care providers' knowledge, attitude and perceived stigma regarding tuberculosis in a pastoralist community in Ethiopia: a cross-sectional study. BMC Health Serv Res. 2019;19(1):19.

20. Wu I. Knowledge and attitudes of healthcare workers towards tuberculosis patients and the experiences of tuberculosis patients regarding healthcare workers in Vellore District, Tamil Nadu, South India. 2010. Retrieved March 13, 2012. 2010.

21. Bhebhe LT, Van Rooyen C, Steinberg WJ. Attitudes, knowledge and practices of healthcare workers regarding occupational exposure of pulmonary tuberculosis. African journal of primary health care \& family medicine. 2014;6(1):1-6.

22. Rieder $\mathrm{H}$. Contacts of tuberculosis patients in high-incidence countries. The international journal of tuberculosis and lung disease. 2003;7(12):S333-S6.

23. Fox GJ, Nhung NV, Sy DN, Hoa NL, Anh LT, Anh NT, et al. Household-contact investigation for detection of tuberculosis in Vietnam. New England Journal of Medicine. 2018;378(3):221-9.

24. Tadesse Y, Gebre N, Daba S, Gashu Z, Habte D, Hiruy N, et al. Uptake of isoniazid preventive therapy among under-five children: TB contact investigation as an entry point. PloS one. 2016;11(5):e0155525.

25. Jaganath D, Zalwango S, Okware B, Nsereko M, Kisingo H, Malone L, et al. Contact Investigation for Active Tuberculosis Among Child Contacts in Uganda. Clinical Infectious Diseases. 2013;57(12):1685-92.

\section{Figures}




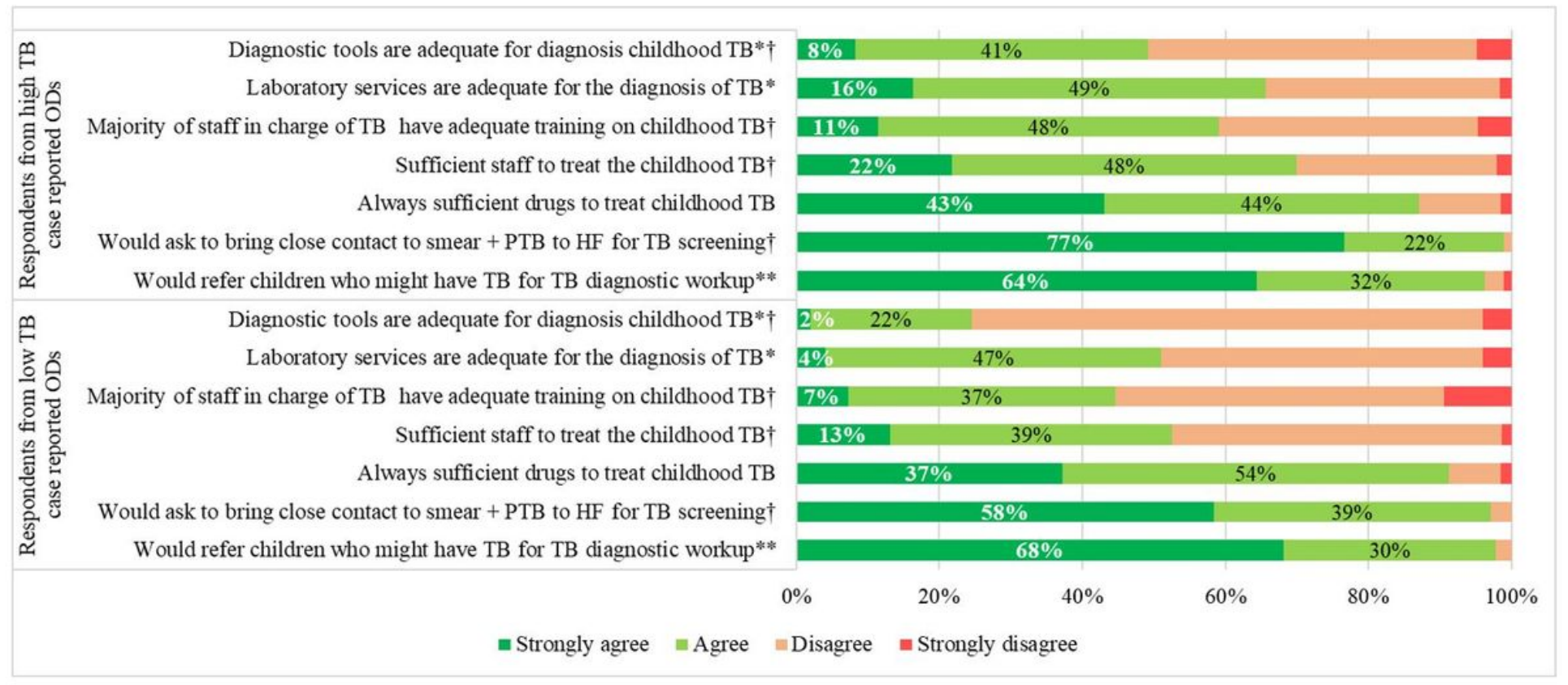

\section{Figure 1}

Attitude toward childhood TB among healthcare providers The horizontal axis of the bar shows the percentages of respondents who strongly agreed, agreed, disagreed, and strongly disagreed with statements used to measure their attitude toward childhood TB. Abbreviation: OD: operational district; TB: tuberculosis; PTB: pulmonary TB; HF: health facilities. $\dagger p<0.05 .{ }^{*}$ Respondents from district referral hospitals only; ${ }^{\star *}$ Respondents from health centers only. 